\title{
Quality of information of websites dedicated to obesity: a systematic search to promote high level of information for Internet users and professionals
}

\author{
Alessandra Perra ${ }^{1}\left[\right.$ D Antonio Preti ${ }^{1} \cdot$ Valerio De Lorenzo $^{2} \cdot$ Antonio Egidio Nardi $^{3} \cdot$ Mauro G. Carta $^{1}$
}

Received: 16 September 2020 / Accepted: 1 December 2020 / Published online: 4 March 2021

(c) The Author(s) 2021

\begin{abstract}
Background The Internet is increasingly used as a source of information. This study investigates with a multidimensional methodology the quality of information of websites dedicated to obesity treatment and weight-loss interventions. We compared websites in English, a language that it is used for the international scientific divulgation, and in Italian, a popular local language.

Methods Level of Evidence: Level I, systematic review search on four largely used search engines. Duplicated and unrelated websites were excluded. We checked: popularity with PageRank; technological quality with Nibbler; readability with the Flesch Reading Ease test or the Gulpease readability index; quality of information with the DISCERN scale, the JAMA benchmark criteria, and the adherence to the Health on the Net Code.

Results 63 Italian websites and 41 English websites were evaluated. English websites invested more in the technological quality especially for the marketing, experience of the user, and mobile accessibility. Both the Italian and English websites were of poor quality and readability.

Conclusions These results can inform guidelines for the improvement of health information and help Internet users to achieve a higher level of information. Users must find benefits of treatment, support to the shared decision-making, the sources used, the medical editor's supervision, and the risk of postponing the treatment.
\end{abstract}

Keywords Obesity · Weight-loss $\cdot$ Health literacy $\cdot$ Information dissemination · Internet $\cdot$ Quality

\section{Introduction}

The prevalence of obesity in the last 50 years has increased and it is considered today as a serious major health challenge worldwide [5]. When measured in terms of body mass index (BMI $=$ a person's weight in kilograms divided by their height in meters squared), the prevalence of people with obesity (BMI $\geq 30 \mathrm{~kg} / \mathrm{m}^{2}$ ) ranges from $3.7 \%$ in Japan to $38.2 \%$ in the United States [5]. Moreover, the percentage of people with obesity is increasing, especially in North Africa and the Americas. In United States, the $42.4 \%$ of the adult

Alessandra Perra

alessandra.perra93@gmail.com

1 Department of Health Sciences and Public Health, University of Cagliari, Cagliari, Italy

2 PRoMIND, Services for Mental Health SRLS, Rome, Italy

3 Federal University of Rio de Janeiro, Rio de Janeiro, Brazil populations has an obesity condition [22]. In Italy, the 54.1\% of the adult population has an overweight condition and just $19.8 \%$ has an obesity condition. Indeed, obesity might represent a milder problem in Italy than in other European countries, but the childhood prevalence is high: $36 \%$ for boys and $34 \%$ for girls $[32,41]$. Obesity is a chronic condition that depends on many factors, principally physical inactivity and overeating; additional risk factors for obesity include medications, psychological factors, disease and social issues [31]. In turn, obesity represents a risk factor for severe metabolic, cardiovascular, degenerative and neoplastic diseases, influencing a sensible decline in life expectancy. It also impacts on the quality of life, increasing the risk of unemployment, hampering socio-economic productivity, and causing a greater occurrence of social disadvantage and disability. To manage such complex and multifactorial condition, it is necessary applying prevention measures such as the promotion of healthy behaviors and health-related treatments $[3,40]$. 
Currently, several international medical organizations have developed specific guidelines for the treatment of obesity [35]. Clinical guidelines are structured recommendations developed to orient health professionals on appropriate health care and health information promotion [26]. They include all the information about the medical condition, the consequences of the condition on health and daily living, the different treatments, also specifying benefits and risk (indications and contraindications, special attention is dedicated to involving patients in the decision-making process [34]. All these components should be present in the correct health information in order to promote high-quality information to the people that are experiencing the condition. Health professionals, administrators, and funders should use guidelines as tools that can reduce the gap between clinical routine and scientific evidence [20], and guarantee the right of equal access and the right of high standards of treatment.

The various guidelines on obesity emphasize the importance of a multidisciplinary approach and the needing to intervene earlier, in primary care settings, with lifestyle intervention [24]. The lifestyle intervention includes the diets for weight loss and physical activity. However, those interventions will only be effective under intensive behavioral therapy approaches. The guidelines underline the chronic nature of obesity and the need for long-term care and the importance of a comprehensive approach to a lifestyle change [35]. For this reason, it is discouraged the proposal of a "magic diet", which often can have adverse effects. For the physical activity depending on a severity level, it is necessary to consult a health professional. Physical activity alone does not have efficacy in promoting long-term weight loss but favor the loss of fat mass and reduce the health risk related to obesity [15]. Most guidelines support 200-300 min per week for long-term weight loss and moderate-intensity physical activity between 150 and $250 \mathrm{~min}$ per week to be effective to prevent weight gain, although that intensity will provide only modest weight loss. All guidelines consider pharmacotherapy as an adjunct treatment to lifestyle changes, especially when BMI $>27$ in association with 1 or more obesity comorbidities or when BMI $>30$, with or without metabolic consequences [19]. Pharmacotherapy for obesity supports diets and in combination with behavioral therapy leads to improve significantly weight loss than either alone. There is a consensus that the patient should be informed about the available drugs and their risk (side effect) and benefits [2]. For people with obesity with BMI greater than or equal to 40 or BMI greater than or equal to 35 with obesity-related comorbid conditions, an alternative is bariatric surgery. Bariatric surgery leads to substantial long-term weight loss, improves many obesity-related comorbid conditions, and reduces mortality [24]. It is considered important that the patients are carefully informed about the complications of the surgery.
In the Digital Era, the access to information about the treatment and the healthy behaviors is rapidly changing, and the individuals searching health information on the Internet have an active role in their health management [13]. It has been estimated that there were 4.39 billion Internet users worldwide in 2019 [21, 25], of whom 312.3 million (95\% of the total American population) were from American countries, and 461.2 (90\% of the total European population) were from European Union. Some studies that were carried out in the U.S. have found that up to $55 \%$ of the Internet population have used the Web to get health or medical information, and the $70 \%$ of those who search health information admit that the Web information influences their decision about how to treat an illness or condition [18]. Currently, the evidence points to the Internet as a hugely used tool for the sharing of medical knowledge and its use is increasing [13]. The practice of shared decision-making between professionals and consumers has the objective to find the best treatment choice for a person [9]. This aspect can have a profound effect on health-related decisions. Indeed, health information on Internet may make patients better informed about health outcomes, services resources, and access thanks to the easy updating process and the potential for interactive formats that promote easy understanding of information [30]. However, health information on the Internet may be inappropriate, or of poor informative quality, misleading, or misinterpreted [17]. The quality of health information available online for healthcare users should not be ignored, because of the important role that has in the health promotion $[4,16]$. However online health information on websites, in general, are inconsistent in quality, especially for reliability. Moreover, the information is often incomplete and the authors or references are omitted [17, 29]. The quality of information about obesity treatment and management on the Internet is not known. Because of the health and economic impact of obesity, it is important to understand better the quality of the online information on this condition. Evaluating the quality of Internet information can be an important way to offer support for Internet users about which kind of information they have necessary to find to promote high-quality level and equity access to online information.

\section{Aims}

This study set out to investigate the readability, accessibility and technological usability, and the quality of information of websites devoted to spreading information about the treatment of obesity and interventions on weight loss in people with obesity. In particular, due to the large usage of the Internet worldwide, we were aimed to comparing websites in two different languages, one language that is used both as a local language and also as a language for the international 
scientific divulgation (English) and one that represents mainly a popular local language (Italian).

\section{Methods}

A systematic search was conducted used the three most common commercial search engines "Google" (www. google.com), "Bing" (www.bing.com), "Yahoo" (www. yahoo.com), and one independent search engine "Duck Go" (duckduckgo.com/), which aims at preserving the privacy of the users. These search engines share more than the $98 \%$ of all searches worldwide and across the platforms, such as desktop, tablet, or mobile [37].

The following key terms were used: "Obesity therapy/ Obesity weight loss" in English and "Terapia obesità/Dimagrimento obesità" in the Italian language. The websites were selected in order of appearance, the first 20 for each English and Italian key term in each search engine. There is evidence that users concentrate their exploration of the websites that are retrieved from a search engine to the first ten entries and rarely go beyond the first two pages of the results [23]. Discussion or forums websites, websites requiring password or payment, not written document (video, only title text, advertisement), and scientific articles were excluded. The search engines were assessed from March 16th to 31st 2020. The evaluation was done blind with the average of the results of two researchers. Popularity of the website was checked via Google's PageRank with https://checkpagerank. net/ (Google's page rank), Google's PageRank is one of the methods Google uses to determine a page's relevance or importance [11].

Technological quality of the website was checked with Nibbler at https://nibbler.silktide.com/ using the following indexes: overall; accessibility; experience; marketing; technology; mobile. Each website was assessed for its accessibility (such as ease of locating information on the website, URL format, and page titles), the rated user experience (such as the content value, format, mobile availability, internal links, etc.), the marketing (links to social media, popularity, meta tags, freshness, etc.) and the quality of informatics used [1].

Readability for the English websites was assessed using the Flesh Kincaid Reading Ease and the Flesh Kincaid Grade Level, tested with the readability test tool of WebFX at the following address: https://www.webfx.com/tools/read-able/. The Flesch Reading Ease score takes into account factors such as the number of words per sentence and the number of syllables per word to give a score from 0 to 100 , with a high-scoring text being more easily understood than one with a low score. A text with a score of 71-100 is considered 'easy' to read, with the average 11-year-old able to read it with ease. A score of 61-70 is considered of 'standard' difficulty, with children aged 13-15 years being able to read it. A text with a score of 60 or below is considered 'difficult' to read $[14,28]$.

Readability for the Italian websites was assessed using the Gulpease readability Index [27], testing at the following address https://farfallaproject.org/readability_static/. The Gulpease index takes into account the length of a word in characters rather than in syllables, which proved to be more reliable for assessing the readability of Italian texts. The index ranges from 0 that means lowest readability to 100 maximum readability [39]. Since the Flesh Kincaid reading test and the Gulpease readability Index, which is tailored for the Italian language, are not directly comparable, readability has been compared between languages on the degree of complexity. The degree of complexity has been grouped into three class: "easily readable" (for texts that the average 11-year-old should be able to read); "standard level of readability" (for texts that children aged 13-15 years old should be able to read); and "difficult to read" (for texts that require high school or a even higher level of literacy).

Quality of the information provided by the website at the specific web page dedicated to the topic was assessed with the DISCERN scale, the JAMA benchmark criteria, and the adherence to the Health on the Net code (HONcode). DISCERN is an instrument designed to help users of consumer health information judge the quality of written information about treatment choices [9]. It is consisting of 16 items, each criterion is rated on a scale from 1 to 5 . Higher is the level better is the quality of information. It is dived into three main sections assessing the reliability, whether it can be trusted as a source of information about treatment choice; the quality of information; and the overall quality [10, 28]. The JAMA benchmark criteria range from 0 to 4 , and it is aimed at to critically judge the credibility, reasonability, and utility of medical information read on the Internet [36]. The JAMA benchmark criteria assess the following core standards: website authorship had to formally include authors, contributors, affiliations, and credentials, attribution should include references and sources used for the content, and copyright information; disclosures should include details about sponsorship, advertising, commercial funding, potential conflicts of interests; currency should include the date of posted and updated information [36]. The HONcode certification was proposed by the Health On the Net Foundation (HON) and certificates the quality of the medical information provided on the Internet [6].

\section{Statistics}

All data were coded in Excel and analyzed using the Statistical Package for Social Sciences (SPSS) version 20. Additional analyses were carried out in R [33]. All tests were two tailed. Due to the explorative nature of the analysis, 
significance threshold was set at $p<00.05$. Means with standard deviations were reported for continuous variables. Counts and percentages were reported for categorical variables. Continuous variables were compared between groups with a non-parametric test (Mann-Whitney $U$ test). Chi-square tests or Fisher's exact tests were used to analyze categorical data. Intra-rater reliability for the JAMA benchmark criteria and the DISCERN scale was assessed with the intraclass correlation coefficient (ICC), with 95\% Confidence Interval (CI). ICC values $\geq 0.60$ are considered acceptable [8].

\section{Results}

The initial sample consisted of 320 websites (160 Italian websites and 160 English websites). We excluded 73 Italian duplicates websites and 75 English duplicates websites. At the end of the screening we excluded 24 Italian websites ( 2 scientific paper, 22 document or not written information) and 44 English websites (3 requiring password, 22 scientific paper, 19 document or not written information and 5 not pertinent). Finally, we analyzed 63 Italian websites and 41 English websites (Fig. 1). Table 1 in ESM lists the main characteristics of the analyzed websites.

The key terms retrieved more "Obesity weight loss" related English websites than "Obesity therapy" related English websites. The reverse was found for the Italian websites. The percentage of retrieval by key terms did not violate the expected $50 \%$ probability at the binomial test ( $p>0.20$ in both comparisons). Google contributed to about half of retrieved websites, but the other search engines contributed as well with a percentage of unique websites (websites that were not listed in the other search engines), with no difference by language. As far as the Google rank of the retrieved websites was concerned, those in the English language had a higher rank than those in the Italian language, hence they were more popular, likely a reflection of the greater fraction of English-speaking users among Internet users (see Table 1 in ESM for details).

\section{Technological quality of the websites}

Overall, the technological quality of the websites concerning the treatment of obesity was good, with a global average Nibbler score above 80\% (Table 1 in ESM).

English websites provided a better experience of use, did a more appropriate use of marketing and were more tailored for use with mobile than the Italian websites. No differences were found in the accessibility to the site or the use of technology.

\section{Readability}

Readability, as measured with the Flesh Kincaid test or the Gulpease readability index, suggested that the websites were on average difficult to read. Italian websites were on average more difficult to read than the English websites (see Table 1 in ESM for details).

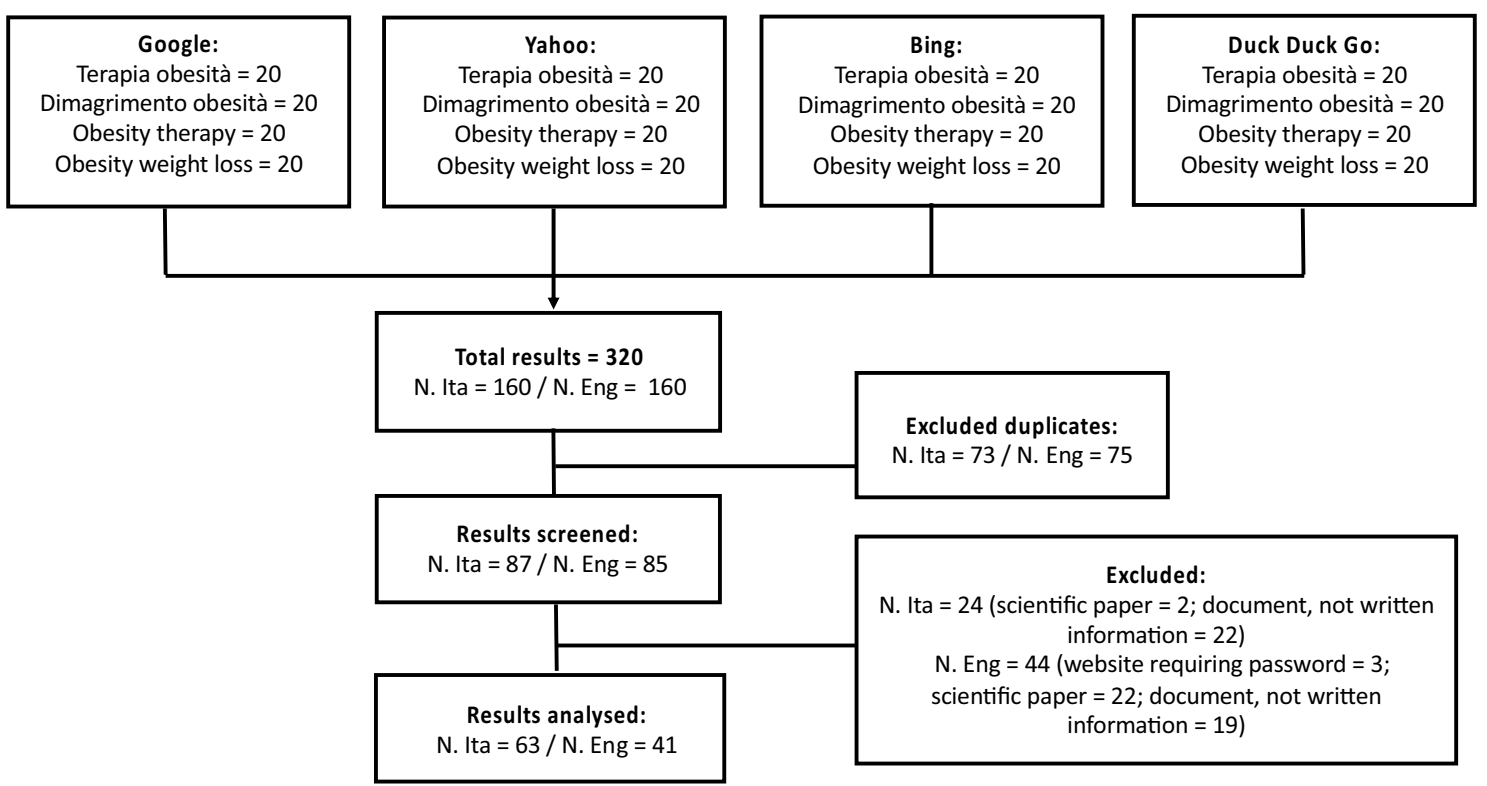

Fig. 1 Flowchart of search results, with all steps of the procedure 


\section{Information quality: adherence to the HONCode}

Only a minority of the assessed websites bothered to acquire a certification of adherence to the HONCode. English websites were more likely to present the certification of adherence to the HONCode than the Italian websites (see Table 1 in ESM for details).

\section{Information quality: JAMA benchmark criteria}

Intra-rater reliability for the JAMA benchmark criteria was poor: $\mathrm{ICC}=0.497 ; 05 \% \mathrm{CI}=0.319-0.638)$. Thus, results concerning the JAMA benchmark criteria should be considered with caution. The JAMA benchmark criteria were rarely complied with, especially for "authorship" and "attribution", which rarely were observed in both the Italian and the English websites at a level of much (3) or completely (4) satisfied (Fig. 2). The criteria of "disclosure" and "currency" were more often met. English websites were more likely to satisfy the "attribution" and "disclosure" criteria than Italian websites (details in Table 1 in ESM).

\section{Information quality: DISCERN scale}

Intra-rater reliability for the DISCERN scale was excellent: $\mathrm{ICC}=0.935 ; 05 \% \mathrm{CI}=0.915-0.952$ ).
English websites were likely to achieve a score of 4 or 5 on the DISCERN items, with some limitations about uncertainty (item 8), risk of treatment, no treatment and support for shared decision-making (items 11, 12 and 15). Up to $20 \%$ of the websites had an overall quality score of 4 or 5 (Fig. 3). Italian websites had a poorer performance on the DISCERN scale, and on items pertaining to the treatment (pro and cons, risk and so on), rarely met the best score of 4 or 5 (Fig. 4). According to the DISCERN scale, the reliability and overall quality of information were estimated to be better in English websites than in Italian websites discussing obesity treatment or weight loss interventions (see details in Table 1 in ESM).

\section{Discussion}

This study highlights which kind of information is detailed in the Internet websites dedicated to obesity treatment for online users to achieve high-quality information promotion. To have a better grasp of this topic, we evaluated the quality information on different websites in a language used also for international divulgation and a popular language and we focused on the quality level and how the differences in quality can impact on the information goals. English websites regarding information about the treatment of obesity and
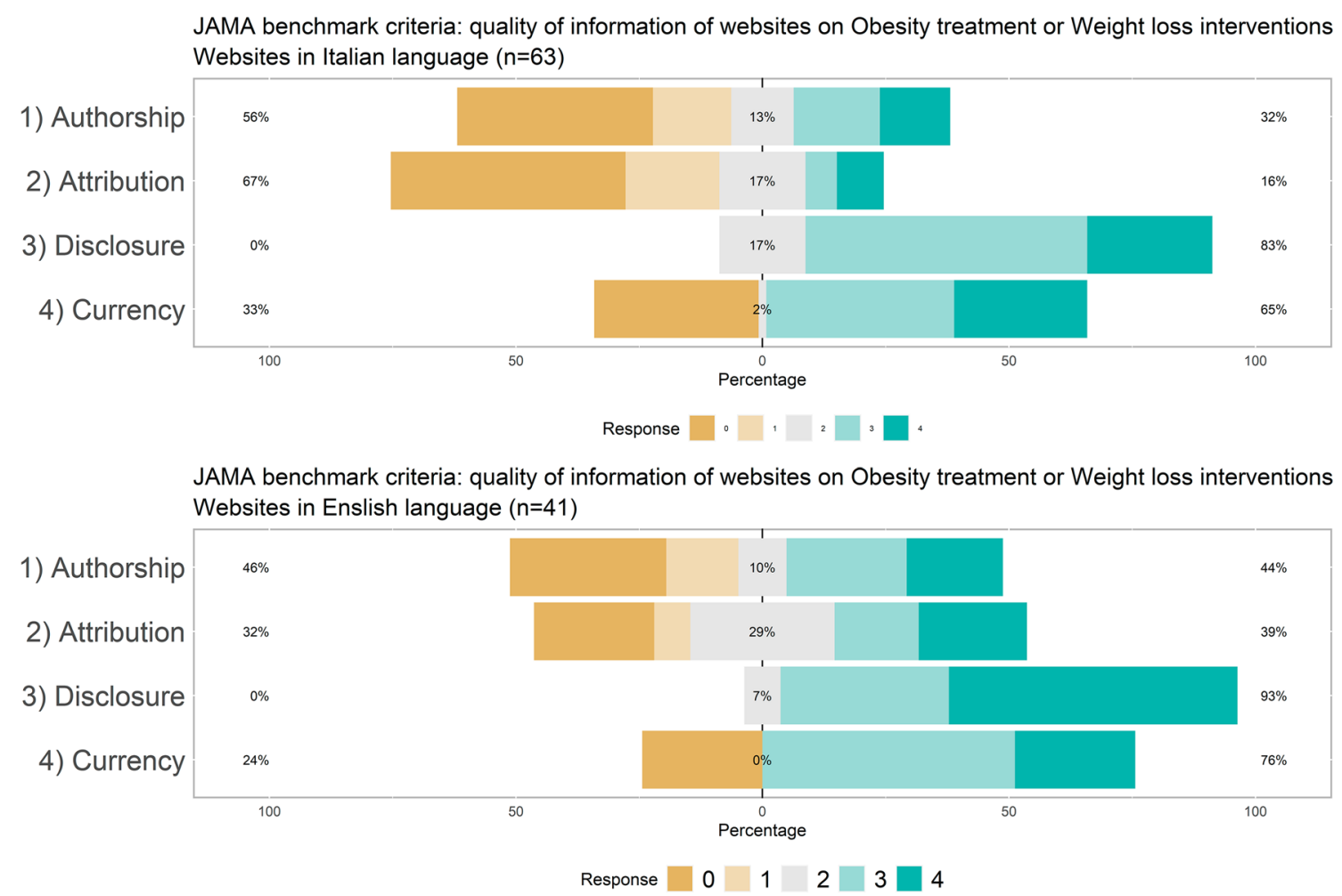

Fig. 2 Distribution of the adherence to the JAMA benchmark criteria in Italian (top) and English (bottom) websites 


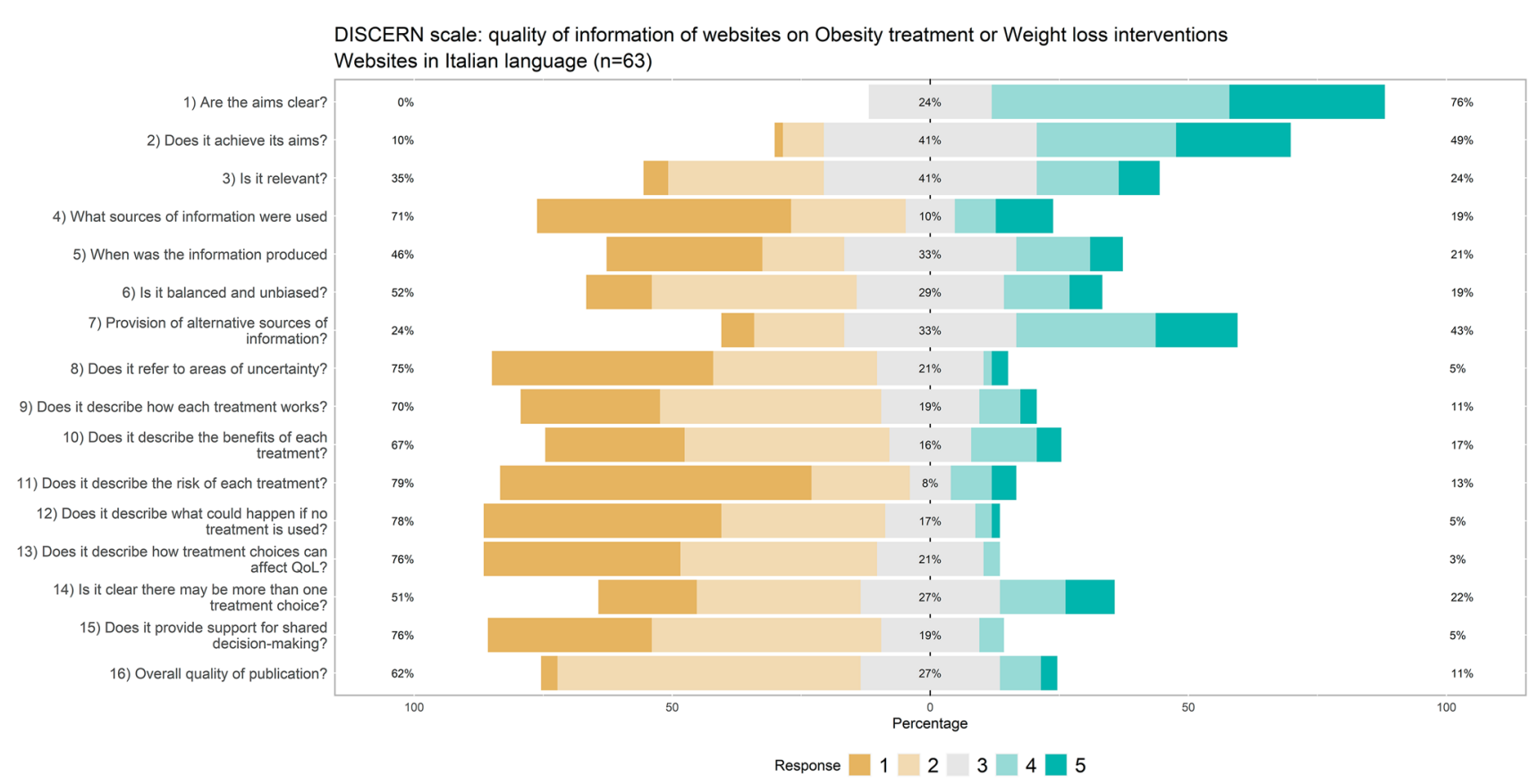

Fig. 3 Distribution of DISCERN-scores combined and averaged across English websites ( $1=$ low, $5=$ high). Adapted from Charnock et al. [9]

interventions on weight loss in people with obesity were, of English websites [1,28]. English websites invested more

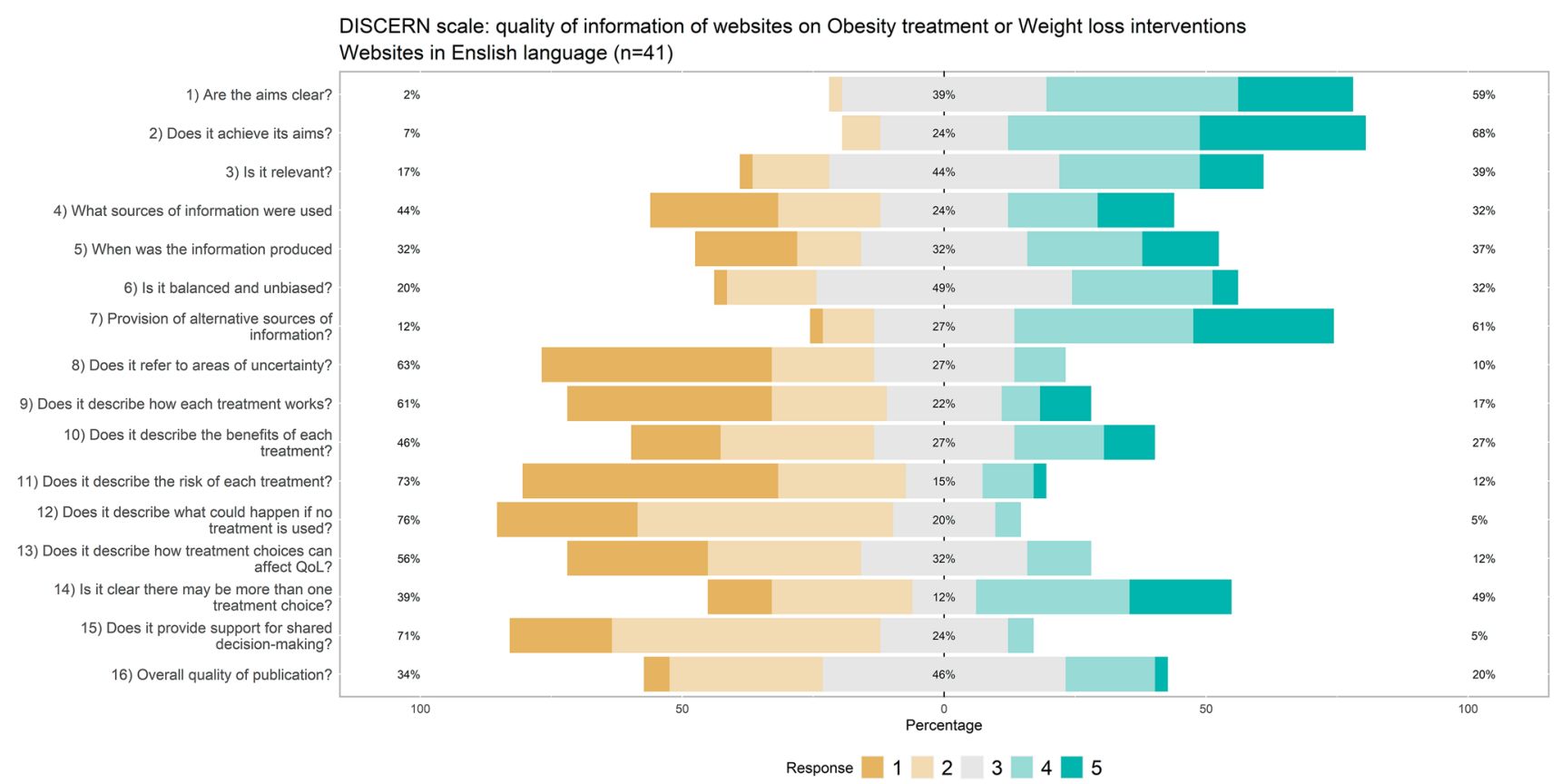

Fig. 4 Distribution of DISCERN-scores combined and averaged across Italian websites $(1=$ low, $5=$ high $)$. Adapted from Charnock et al. [9]

in general, better than the Italian websites. In particular, the Italian websites were more difficult to read, although in both languages the websites were, on average, difficult to read, as seen in the past in other studies that evaluated the readability in the experience of the user and mobile accessibility, an essential feature currently, since a large part of the web traffic pass now on mobile phones. Greater technological quality 
in these domains resulted in better marketing of the English websites compared to the Italian ones.

The analysis based on the JAMA Benchmark criteria showed that the Italian websites had a lower quality in terms of attribution and disclosure. In general, both the Italian and the English websites were of poor quality as far as the authorship and attribution were concerned; the adherence to the HONcode certification was also poor, with a global scarce adherence, but better results in the English websites. On the DISCERN tool, too, Italian websites had poorer performances, especially for the uncertainty, risk of treatment, risk if no treatment is used and support for shared decision making (items $8,11,12,15$ ). A lot of websites do not have a clear focus about the source of information used and the expert assessment. Moreover, not all types of treatments are always described, there is a little attention to the risks and benefits of each treatment and there is a not clear information about the long-term lifestyle changes.

In general, the websites dedicated to obesity treatment and weight loss should have better information about treatment and about the chronic nature of obesity that leads a long-term care and the importance of comprehensive approach to lifestyle change [35].

This is the first contribution, in our knowledge, that evaluates the quality of obesity treatment comparing different language websites to suggest and promote specific quality health information to orient Internet users all over the world. As in the other studies mentioned before, in general, the health information also in this specific topic doesn't show a high level of quality information and easy readability on Internet websites worldwide.

It should be borne in mind that most websites, especially those in the English language, were dedicated to specific topics (pharmacotherapy or bariatric surgery) and were aimed at users that already were looking for something so specific. Their prominence in the rank of the search engine depended on algorithms that emphasize the number of searches, links to the page, and the number of clicks on the website by users. Nevertheless, since users often only take a look at the first records in a search, it is important that websites devoted to a health topic offer the most comprehensive list of information about that topic, to avoid a biased view by part of the users.

\section{Implications for the clinics}

Considering the increasing rate of people with obesity and the impact of the online search for own health-related problems and about the choices of treatments, it is necessary having access to cheap and effective interventions [38]. To achieve this goal, it is important to improve the quality of online information and treatment accessibility [12]. Low quality of web information contributes to reducing the promotion of correct health information for internet users. To address a complex health condition like obesity, it is important to have access to information about all the different treatment options and on the lifestyle changes in the long term that are important to manage the condition. Poor quality of Internet information represents a limit for equal access to information about different treatments. Clinicians and Internet reviewers should be requested to write healthcare information in a manner accessible to all, with a clear definition of the goals and the risks of all treatments, also promoting shared decision making. According to the International Guidelines on the topic, the Internet users have to found clearly an emphasis on the different treatments related to the different conditions of obesity [24]. In particular, it should be always present the indication for a comprehensive lifestyle intervention, that includes building a skill set of behavioral knowledge and strategies to achieve and maintain dietary and physical activities in a long term [35]. The guidelines emphasize the chronic nature of obesity and the need for long-term care and also focus the objective of weight loss not for esthetic problems but for improving the health condition [7]. Dietary recommendations emphasize reducing intake of food and fat by $500-1000 \mathrm{cal} / \mathrm{day}$. In addition, physical activity, varying from a minimum of $150 \mathrm{~min}$ a week to $300 \mathrm{~min} /$ week, is widely recommended. Recommendations concerning pharmacotherapy in most guidelines restricted its use to patients with BMI exceeding $30 \mathrm{~kg} / \mathrm{m}^{2}$. Bariatric surgery is recommended when BMI $>40$ for patients in whom other treatment approaches failed [34]. For each treatment, users have also to find the benefits and the risk about the treatment, a support to the shared decision making, the risk to postpone the treatment. It is also important to be sure that are valid and high-quality level that users can access to the sources used and that in the websites were made an editor medical review (Table 2 in ESM websites DISCERN criteria for the quality evaluation, that can help to find the correct information).

\section{Implication for research}

To monitoring and support the process of online sharing of health information, it is important to define a clear evaluation methodology for the quality, accessibility and technological aspects of Internet information. It is as well important to monitor the quality of websites across countries to avoid that only English speakers can have access to highquality information. For example, the adherence to HONcode certification is in general associated with websites of the highest quality [13], but Italian websites rarely adhere to the HONcode. Thus, it could be useful to create guidelines in different languages to promote a high standard for writing online health information both for professional and users. 


\section{Strengths and limitations}

The methodology that was used in this study is under development and for some of the tools there still some degree of uncertainty about the process of attribution of the score. Moreover, the intra-raters reliability of the JAMA Benchmark criteria was low, leaving open the question on the reproducibility of the evaluation based on this tool. However, even if this methodology is under development, we selected standardized and multidimensional methods for a global evaluation of the quality information. Of course, we need more studies to better define an international methodology.

\section{What is already known on this subject?}

Internet is used as an important source of health information and as a tool for the sharing of medical knowledge. It may make patients better informed. But at this point, the quality information in general are inconsistent in terms of quality and also for the methodology of evaluation.

\section{What this study adds?}

This study adds a multidimensional methodology for the quality evaluation specific for Internet health websites, suggest and inform Internet users in order to looking for a highquality health information and also for the health workers to better improve the information available online according to the guideline about the treatment for Obesity condition. In the Digital Era, a good level of Internet health information it can be part of the prevention process and helps public health services.

\section{Conclusions}

The quality of Internet information does not reach a high level worldwide. In the Digital Era, monitoring and evaluating the standard of online health information is an important scope of investigation, to ensure the rights of equal and high quality of health information access. This study is a first step to creating a multidimensional and standardized quality assessment of health information in the Internet that offer a useful tip for searching health information online.

Supplementary Information The online version contains supplementary material available at (https://doi.org/10.1007/s40519-020-01089 $-\mathrm{x})$.
Funding Open access funding provided by University of Cagliari within the CRUI-CARE Agreement.

\section{Compliance with ethical standards}

Conflict of interest The authors declare that they have no conflict of interest.

Ethical approval This article does not co contain any studies with human partecipants or animal performed by any of the authors.

Informed consent For this type of study formal consent is not required.

Open Access This article is licensed under a Creative Commons Attribution 4.0 International License, which permits use, sharing, adaptation, distribution and reproduction in any medium or format, as long as you give appropriate credit to the original author(s) and the source, provide a link to the Creative Commons licence, and indicate if changes were made. The images or other third party material in this article are included in the article's Creative Commons licence, unless indicated otherwise in a credit line to the material. If material is not included in the article's Creative Commons licence and your intended use is not permitted by statutory regulation or exceeds the permitted use, you will need to obtain permission directly from the copyright holder. To view a copy of this licence, visit http://creativecommons.org/licenses/by/4.0/.

\section{References}

1. Al Wattar BH, Pidgeon C, Learner H, Zamora J, Thangaratinam S (2016) Online health information on obesity in pregnancy: a systematic review. Eur J Obstet Gynecol Reprod Biol 206:147-152. https://doi.org/10.1016/j.ejogrb.2016.09.016

2. Apovian CM, Aronne LJ, Bessesen DH et al (2015) Pharmacological management of obesity: an endocrine Society clinical practice guideline [published correction appears in J ClinEndocrinolMetab. 2015 May;100(5):2135--6]. J ClinEndocrinolMetab 100(2):342-362. https://doi.org/10.1210/jc.2014-3415

3. Barros JM, Duggan J, Rebholz-Schuhmann D (2020) The application of internet-based sources for public health surveillance (infoveillance): systematic review. J Med Internet Res 22(3):e13680. https://doi.org/10.2196/13680

4. Beaunoyer E, Arsenault M, Lomanowska AM, Guitton MJ (2017) Understanding online health information: evaluation, tools, and strategies. Patient Educ Couns 100(2):183-189. https://doi. org/10.1016/j.pec.2016.08.028

5. Blüher M (2019) Obesity: global epidemiology and pathogenesis. Nat Rev Endocrinol 15(5):288-298. https://doi.org/10.1038/s4157 4-019-0176-8

6. Boyer C, Baujard V, Geissbuhler A (2011) Evolution of health web certification through the HONcode experience. Stud Health Technol Inform 169:53-57

7. Bray GA, Heisel WE, Afshin A et al (2018) The science of obesity management: an endocrine society scientific statement. Endocr Rev 39(2):79-132. https://doi.org/10.1210/er.2017-00253

8. Brennan P, Silman A (1992) Statistical methods for assessing observer variability in clinical measures. BMJ 304:1491-1494

9. Charnock D (1998) The DISCERN handbook. Radcliffe Medical Press, Oxon

10. Charnock D, Shepperd S, Needham G, Gann R (1999) DISCERN: an instrument for judging the quality of written consumer health information on treatment choices. J Epidemiol Community Health 53(2):105-111. https://doi.org/10.1136/jech.53.2.105 
11. Chen P, Xie H, Maslov S, Redner S (2007) Finding scientific gems with Google's PageRank algorithm. J Inform 1(1):8-15

12. Cline RJ, Haynes KM (2001) Consumer health information seeking on the Internet: the state of the art. Health Educ Res 16(6):671-692. https://doi.org/10.1093/her/16.6.671

13. Corcelles R, Daigle CR, Talamas HR, Brethauer SA, Schauer PR (2015) Assessment of the quality of Internet information on sleeve gastrectomy. SurgObesRelat Dis 11(3):539-544

14. D'Alessandro DM, Kingsley P, Johnson-West J (2001) The readability of pediatric patient education materials on the World Wide Web. Arch Pediatr Adolesc Med 155(7):807-812. https://doi. org/10.1001/archpedi.155.7.807

15 Donnelly JE, Blair SN, Jakicic JM et al (2009) American College of Sports Medicine Position Stand. Appropriate physical activity intervention strategies for weight loss and prevention of weight regain for adults [published correction appears in Med Sci Sports Exerc. 2009 Jul;41(7):1532]. Med Sci Sports Exerc 41(2):459471. https://doi.org/10.1249/MSS.0b013e3181949333

16. Eysenbach G, Köhler C (2002) Does the internet harm health? Database of adverse events related to the internet has been set up. BMJ 324(7331):239

17. Eysenbach G, Powell J, Kuss O, Sa ER (2002) Empirical studies assessing the quality of health information for consumers on the world wide web: a systematic review. JAMA 287(20):2691-2700. https://doi.org/10.1001/jama.287.20.2691

18. Fox S (2000) The online health care revolution: How the web helps Americans Take better care of themselves. A Pew Internet and American Life Project Online Report. http://www.pewinterne t.org/reports/pdfs/PIP_Health_Report.pdf

19. Garvey WT, Mechanick JI, Brett EM et al (2016) Reviewers of the AACE/ACE Obesity Clinical Practice Guidelines. American Association of Clinical Endocrinologists and American College of Endocrinology comprehensive clinical practice guidelines for medical care of patients with obesity. Endocr Pract 22(Suppl 3): $1-203$

20 Grol R (2001) Successes and failures in the implementation of evidence-based guidelines for clinical practice. Med Care 39(82):II46-II54. https://doi.org/10.1097/00005650-20010 8002-00003

21 Guedes E, Sancassiani F, Carta MG et al (2016) Internet Addiction and Excessive Social Networks Use: What About Facebook? ClinPractEpidemiolMent Health 12:43-48. https://doi. org/10.2174/1745017901612010043 (eCollection 2016)

22. Hales CM, Carroll MD, Fryar CD, Ogden CL (2020) Prevalence of obesity and severe obesity among adults: United States, 2017-2018

23. Jacobsen M (2017) How far down the search engine results page will most people go? Retrieved from https://www.theleverageway. com/blog/how-far-down-the-search-engine-results-page-willmost-people-go/

24. Jensen MD, Ryan DH, Apovian CM et al (2014) 2013 AHA/ACC/ TOS guideline for the management of overweight and obesity in adults: a report of the American College of Cardiology/American Heart Association Task Force on Practice Guidelines and The Obesity Society. Circulation 129(25 suppl 2):S102-S138. https ://doi.org/10.1161/01.cir.0000437739.71477.ee

25. Kemp S (2019) Digital 2019: global digital overview. Retrieved on May, 20, 2019
26. Lohr KN, Field MJ (eds) (1990) Clinical practice guidelines: directions for a new program, vol 90, no 8. National Academies Press, Washington

27. Lucisano P, Piemontese ME (1988) Gulpease: a formula to predict readability of texts written in Italian Language. Scuola Città 39

28. McKearney RM, MacKinnon RC, Smith M, Baker R (2018) Tinnitus information online-does it ring true? J Laryngol Otol 132(11):984-989. https://doi.org/10.1017/S0022215118001792

29. Morahan-Martin JM (2004) How internet users find, evaluate, and use online health information: a cross-cultural review. Cyberpsychol Behav 7(5):497-510. https://doi.org/10.1089/cpb.2004.7.497

30 Murray E, Lo B, Pollack L et al (2003) The impact of health information on the Internet on health care and the physician-patient relationship: national U.S. survey among 1.050 U.S. physicians. J Med Internet Res 5(3):e17. https://doi.org/10.2196/jmir.5.3.e17

31. National Center for Health Statistics (2019) National Health and Nutrition Examination Survey. http://www.cdc.gov/nchs/nhane s.htm

32. OECD (2014) The size and risks of the international epidemic of child obesity. Italy update 2014 , in obesity and the economics of prevention: fit not fat, OECD obesity update 2014

33. R Core Team (2018) R: a language and environment for statistical computing. R Foundation for Statistical Computing, Vienna. http://www.R-project.org/

34 Reis ECD, Passos SRL, Santos MABD (2018) Quality assessment of clinical guidelines for the treatment of obesity in adults: application of the AGREE II instrument. Cad Saude Publica 34(6):e00050517. https://doi.org/10.1590/0102-311X00050517

35. Ryan DH, Kahan S (2018) Guideline recommendations for obesity management. Med Clin North Am 102(1):49-63. https://doi. org/10.1016/j.mcna.2017.08.006

36. Silberg WM, Lundberg GD, Musacchio RA (1997) Assessing, controlling, and assuring the quality of medical information on the Internet: caveant lector etviewor-Let the reader and viewer beware. JAMA 277(15):1244-1245

37. StatCounter Global Stats (2020) 2020 top 5 desktop, tablet, mobile \& console search engines from January 2019 to April 2020. Retrieved from https://gs.statcounter.com/search-engine-marke t-share\#monthly-201901-202004

38 Thangaratinam S, Rogozinska E, Jolly K et al (2012) Effects of interventions in pregnancy on maternal weight and obstetric outcomes: meta-analysis of randomised evidence. BMJ 344:e2088. https://doi.org/10.1136/bmj.e2088

39. Tonelli S, Manh KT, Pianta E (2012) Making readability indices readable. In: Proceedings of the first workshop on predicting and improving text readability for target reader populations. Association for Computational Linguistics, pp 40-48

40. World Health Organization (1986) The Ottawa charter for health promotion: first international conference on health promotion, Ottawa, 21 November 1986. WHO, Geneva

41. World Health Organization (2013) Global health observatory data repository (online database), climate change and health, burden of disease. WHO, Geneva

Publisher's Note Springer Nature remains neutral with regard to jurisdictional claims in published maps and institutional affiliations. 